\title{
Effects of Alloying Elements on Creep Properties of 9Cr-3.3W-0.5Pd-V, Nb, N, B Steels
}

\author{
Hirokazu OKADA, Seiichi MUNEKI, Katsumi YAMADA, Hiroshi OKUBO, Masaaki IGARASHI ${ }^{1)}$ and Fujio ABE \\ Steel Research Center, National Research Institute of Materials Science, Sengen, Tsukuba, Ibaraki 305-0047 Japan. \\ 1) Corporate Research and Development, Sumitomo Metal Industries, Ltd., Fuso-cho, Amagasaki, Hyogo 660-0891 Japan.
}

(Received on April 23, 2002; accepted in final form on June 20, 2002)

\begin{abstract}
Owing to the fine precipitations of FePd $L 1_{0}$ type ordered phase $\alpha^{\prime \prime}$, Pd addition to $9 \mathrm{Cr}$ ferritic heat resistant steel improves the creep strength by not only reducing the creep rate but also extending the creep rupture life. In this study, effects of alloying elements on creep properties of Pd added $9 \mathrm{Cr}$ ferritic steels have been evaluated with $10 \mathrm{~kg}$-ingots in order to search for substitutional element for the precious metal Pd. Among the metals from VIIA to IB except Fe and TC, some elements were found to harden the steels aged at around $823 \mathrm{~K}$, which is the precipitation temperature of $\alpha^{\prime \prime}$. Corresponding to the hardness change, some elements were found to improve the creep properties also. Among such elements, especially Re addition prevented the growth of Laves phase and remarkably reduced the minimum creep rate at lower stress level. From these results, pipe fabrication and welding tests were performed on $\mathrm{Pd}$ and $\mathrm{Re}$-added $\mathrm{9Cr}$ steel using $180 \mathrm{~kg}$-ingots. It was found that this steel could easily be welded by gas tungsten arc welding and formed into pipe without harmful defects.
\end{abstract}

KEY WORDS: ferritic steels; FePd; L1 10 type ordered intermetallic phase; creep; microstructure.

\section{Introduction}

High $\mathrm{Cr}$ ferritic steels such as ASME P91 steel have been successfully used for large diameter and thick section boiler components such as main steam pipe and header in super critical boilers in fossil-fired power plants. ${ }^{1)}$ Recent trend to utilization of clean energy leading to protection of global environment has been accelerating application of ultra super critical (USC) boilers, which are operated with higher efficiency in power generation than in conventional ones and thus release less amount of carbon dioxide. ${ }^{2,3)}$ The USC boilers require new steels with improved creep strength and steam-oxidation resistance at elevated temperatures over $873 \mathrm{~K}$, because of the increase in operating temperature and pressure of the steam. Addition of $\mathrm{W}$ to the steel has been found to be effective to increase creep rupture strength at high temperatures and has already been used in some newly developed steels such as P92 and P122 for the USC boilers. ${ }^{4)}$

A typical initial microstructure of these steels consist of tempered lath-martensite matrix with dislocation density of the order of $10^{14} / \mathrm{m}^{25,6)}$ and $\mathrm{M}_{23} \mathrm{C}_{6}$ (M: $\mathrm{Cr}, \mathrm{Fe}, \mathrm{Mo}$, W etc.) type carbides along prior austenite grain boundary as well as packet, block and lath boundaries. $\left.{ }^{7}\right) \mathrm{MX}(\mathrm{M}: \mathrm{V}, \mathrm{Nb}$ etc. and $\mathrm{X}: \mathrm{C}, \mathrm{N})$ type carbonitrides are considered to form mainly inside lath, although some are found to form along the boundaries because of the preferential nucleation on the dislocations during tempering. ${ }^{8,9)}$ The addition of $\mathrm{W}$ to the steels sometimes enhances precipitation of intermetallic phases such as Laves and $\mu$ phases mainly along prior austenite grain boundaries and lath boundaries, and also inside grain during long-term exposure at high temperatures. ${ }^{10)}$ FePd-based $\mathrm{L1}_{0}$ type ordered phase $\alpha^{\prime \prime}$ has recently been found to form coherently inside the grains in the steels with $\mathrm{Pd}$ and to be useful to increase the creep resistance like MX carbonitride. ${ }^{11)}$

In this study, effects of alloying elements on creep properties of $\mathrm{Pd}$ added $9 \mathrm{Cr}$ ferritic steels have been evaluated in order to search for substitutional element for the precious metal Pd. Then pipe fabrication and welding test were done to confirm the possibility to apply $\mathrm{Pd}$ added $9 \mathrm{Cr}$ steel to large diameter and thick-wall boiler components.

\section{Experimental Procedure}

\subsection{Fundamental Test}

Table 1 shows the chemical compositions of the tested steels. Pd concentrations were varied from 0 to 1.5 mass $\%$ : B1 to B4. 0.5\% Pd steel: B2 was selected as base steel, and various metals, from VIIA to IB except $\mathrm{Fe}$, Tc and $\mathrm{Pd}$, were added with 0.5 mass $\%$ to the base steel: B5 to B7, C1 to C6, D1, D2 and D4. $10 \mathrm{~kg}$-ingots were prepared by vacuum induction melting. The ingots were hot forged and rolled into $16 \mathrm{~mm}$ square bars. All bars were normalized at $1373 \mathrm{~K}$ for $0.5 \mathrm{~h}$.

Softening behaviors of the steels were examined with tempering from 773 to $1113 \mathrm{~K}$ for 1 to $20 \mathrm{~h}$. After tempering at $1043 \mathrm{~K}$ for $4 \mathrm{~h}$, creep tests were conducted at $923 \mathrm{~K}$ with 120 and $100 \mathrm{MPa}$. The dimension of the creep test specimen was $8 \mathrm{~mm}$ in diameter and $42 \mathrm{~mm}$ in gauge 
Table 1. Chemical compositions of the steels for the fundamental test. (mass\%)

\begin{tabular}{cccccccccccc}
\hline Mark & $\mathrm{C}$ & $\mathrm{Si}$ & $\mathrm{Mn}$ & $\mathrm{Cr}$ & $\mathrm{W}$ & $\mathrm{V}$ & $\mathrm{Nb}$ & $\mathrm{N}$ & $\mathrm{B}$ & $\mathrm{Pd}$ & Others \\
\hline B1 & 0.07 & 0.29 & 0.47 & 8.9 & 3.2 & 0.19 & 0.05 & 0.06 & 0.005 & - & - \\
B2 & $\mathbf{0 . 0 7}$ & $\mathbf{0 . 3 2}$ & $\mathbf{0 . 4 9}$ & $\mathbf{8 . 8}$ & $\mathbf{3 . 2}$ & $\mathbf{0 . 1 9}$ & $\mathbf{0 . 0 5}$ & $\mathbf{0 . 0 5}$ & $\mathbf{0 . 0 0 5}$ & $\mathbf{0 . 5 6}$ & - \\
B3 & 0.08 & 0.31 & 0.50 & 9.0 & 3.2 & 0.19 & 0.05 & 0.06 & 0.005 & $\mathbf{1 . 1 2}$ & - \\
B4 & 0.08 & 0.31 & 0.50 & 9.0 & 3.3 & 0.19 & 0.05 & 0.06 & 0.005 & $\mathbf{1 . 6 2}$ & - \\
B5 & 0.08 & 0.27 & 0.49 & 8.8 & 3.2 & 0.18 & 0.04 & 0.06 & 0.005 & 0.59 & Co: $\mathbf{0 . 4 9}$ \\
B6 & 0.08 & 0.32 & 0.50 & 8.8 & 3.2 & 0.19 & 0.05 & 0.06 & 0.005 & 0.56 & Ni: 0.50 \\
B7 & 0.08 & 0.31 & 0.50 & 9.0 & 3.3 & 0.18 & 0.05 & 0.05 & 0.005 & 0.56 & Cu: 0.50 \\
C1 & 0.08 & 0.27 & $\mathbf{0 . 9 8}$ & 8.9 & 3.3 & 0.19 & 0.05 & 0.06 & 0.005 & 0.58 & (Mn) \\
C2 & 0.08 & 0.31 & 0.50 & 9.0 & 3.3 & 0.19 & 0.05 & 0.06 & 0.005 & 0.56 & Ru: 0.47 \\
C3 & 0.08 & 0.30 & 0.50 & 9.1 & 3.3 & 0.19 & 0.05 & 0.06 & 0.005 & 0.56 & Rh: $\mathbf{0 . 5 4}$ \\
C4 & 0.08 & 0.30 & 0.50 & 9.0 & 3.2 & 0.19 & 0.05 & 0.06 & 0.005 & 0.56 & Re: $\mathbf{0 . 4 7}$ \\
C5 & 0.08 & 0.30 & 0.49 & 9.0 & 3.2 & 0.19 & 0.05 & 0.06 & 0.007 & 0.56 & Os: 0.49 \\
C6 & 0.08 & 0.30 & 0.50 & 9.0 & 3.2 & 0.19 & 0.05 & 0.06 & 0.005 & 0.56 & Ir: 0.48 \\
D1 & 0.08 & 0.31 & 0.50 & 9.0 & 3.1 & 0.19 & 0.05 & 0.07 & 0.005 & 0.56 & Au: 0.52 \\
D2 & 0.08 & 0.30 & 0.49 & 8.8 & 3.2 & 0.19 & 0.05 & 0.06 & 0.005 & 0.56 & Pt: 0.41 \\
D4 & 0.08 & 0.28 & 0.49 & 9.0 & 3.3 & 0.19 & 0.05 & 0.06 & 0.006 & 0.57 & Ag: $\mathbf{0 . 2 8}$ \\
\hline
\end{tabular}

Table 2. Chemical compositions of the steels for the demonstrational test. (mass\%)

\begin{tabular}{lccccccccccc}
\hline Mark & $\mathrm{C}$ & $\mathrm{Si}$ & $\mathrm{Mn}$ & $\mathrm{Cr}$ & $\mathrm{W}$ & $\mathrm{V}$ & $\mathrm{Nb}$ & $\mathrm{N}$ & $\mathrm{B}$ & $\mathrm{Pd}$ & Others \\
\hline MA1 & 0.10 & 0.34 & 0.43 & 8.7 & - & 0.23 & 0.08 & 0.04 & 0.0001 & - & Mo: 0.98 \\
MB1 & 0.08 & 0.30 & 0.51 & 9.0 & 2.9 & 0.20 & 0.05 & 0.05 & 0.005 & - & - \\
MB2 & 0.08 & 0.30 & 0.51 & 9.0 & 2.9 & 0.20 & 0.05 & 0.05 & 0.005 & - & - \\
MC1 & 0.10 & 0.04 & 0.36 & 9.0 & 2.9 & 0.19 & 0.05 & 0.03 & 0.005 & 0.70 & Re: 0.49 \\
MC2 & 0.10 & 0.04 & 0.37 & 9.1 & 2.9 & 0.19 & 0.05 & 0.03 & 0.004 & 0.69 & Re: 0.49 \\
\hline \multicolumn{7}{l}{ Note: MB2 and MC2 were for pipes. Others were for plates. }
\end{tabular}

Note: MB2 and MC2 were for pipes. Others were for plates.

length. Microstructure of the steels in the tempered and the creep-ruptured conditions were examined under scanning electron microscope (SEM). The amount of precipitates for the creep-ruptured specimens was estimated by the quantitative chemical analysis of extracted residues.

\subsection{Pipe Fabrication and Welding Test}

Table 2 shows the chemical compositions of the steels for this demonstration. From the fundamental test results, $0.5 \mathrm{mass} \%$ of $\mathrm{Re}$ was added to $9 \mathrm{Cr}-0.3 \mathrm{Mn}-9 \mathrm{Cr}-3 \mathrm{~W}-$ 0.7Pd-V, Nb, N, B steel: $\mathrm{MC1}$ and MC2. Mod. 9Cr-1Mo steel: MA1 and the steel equivalent to B1: MB1 and MB2 were also prepared to the test as the references. Three $180 \mathrm{~kg}$-ingots, MA1, MB1 and MC1, were hot forged and rolled into $25 \mathrm{~mm}$ wall thickness plate. Two $180 \mathrm{~kg}$-ingots, MB2 and MC2, were hot forged and hot extruded into pipes. The dimension of the pipe is $84 \mathrm{~mm}$ in outside diameter and $12.5 \mathrm{~mm}$ in wall thickness. All plates and pipes were normalized at $1373 \mathrm{~K}$ for $4 \mathrm{~h}$. MA1, MB1 and MB2 were tempered at $1043 \mathrm{~K}$ for $4 \mathrm{~h}$ and other were tempered at $823 \mathrm{~K}$ for $4 \mathrm{~h}$ followed by tempering at $1043 \mathrm{~K}$ for $4 \mathrm{~h}$. This double tempering, combination of low temperature aging and high temperature tempering, is reported to give the optimum initial microstructure consisting of fine dispersion of the $\alpha^{\prime \prime}$ phase and MX carbonitride inside lath decorated with $\mathrm{M}_{23} \mathrm{C}_{6}$ along lath, block and packet boundaries of martensite as well as along the prior austenite grain boundaries. $^{12)}$ In order to evaluate the applicability of Pd bearing steel to the thick-walled pipes of fossil fired power plants, following tests were conducted. High strain rate tensile tests were performed on the plates with a condition of a heating rate of $100 \mathrm{~K} \cdot \mathrm{min}^{-1}$, a holding time of $30 \mathrm{~min}$, a temperature range from 1273 to $1548 \mathrm{~K}$ and a strain rate of $1 \mathrm{sec}^{-1}$. The plates were also welded with AWS ER Ni Cr-3 filler wire by gas tungsten arc welding (GTAW) and the properties of welded joints were examined. Figure 1 shows the cross section of weld groove. The welding conditions are summarized in Table 3.

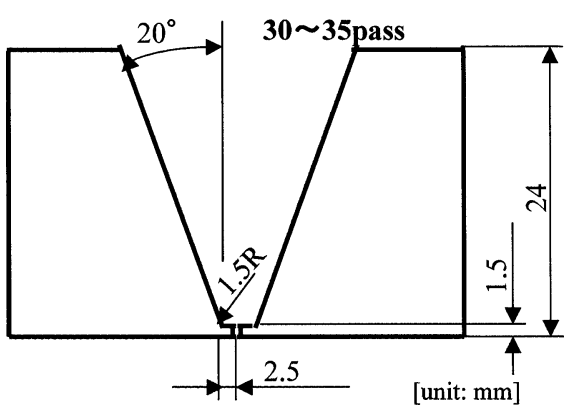

Fig. 1. A cross section of beveling for welding joints.

Table 3. Welding conditions for the plates.

\begin{tabular}{ll}
\hline Item & Condition \\
\hline Method & Gas Tungsten Arc Welding \\
Filler Wire & AWS ER Ni Cr-3 equivalent \\
Arc Current & 1 through 6th pass: 70 - 160A \\
& after 7th pass: $180-200 \mathrm{~A}$ \\
Arc Voltage & $8-16 \mathrm{~V}$ \\
Welding Speed & about $80 \mathrm{~mm} / \mathrm{min}$ \\
Pre Heating & minimum $373 \mathrm{~K}$ \\
Sealing Gas & Ar $(99.9 \%)$ \\
Post Welding Heat Treatment & $1013 \mathrm{~K}$ for $4 \mathrm{~h}$, air cooling \\
\hline
\end{tabular}

\section{Results and Discussion}

\subsection{Fundamental Test}

Figure 2 shows the tempering parameter dependence of the hardness for Pd-added and Pd-free steels. Pd addition hardened the steel at the temperature around $823 \mathrm{~K}$ and the hardness depended on the $\mathrm{Pd}$ concentrations. Figure 3 shows the secondary electron image of $1.5 \% \mathrm{Pd}$ steel: B4 after tempering at $823 \mathrm{~K}$ for $20 \mathrm{~h}$. About $100 \mathrm{~nm}$-length precipitates, arranged in specific directions were observed inside martensite lath. This is because $\mathrm{Fe}-\mathrm{Pd} \mathrm{L} 1_{0}$ type ordered phase: $\alpha^{\prime \prime}$ precipitates coherently and disk-likely inside the ferrite matrix: $\alpha$ with the following crystallographic relationship; $\{001\} \alpha / /\{001\} \alpha^{\prime \prime},\langle 100\rangle \alpha / /\langle 110\rangle \alpha^{\prime \prime}{ }^{11)}$ Hardness after $20 \mathrm{~h}$ tempering at $823 \mathrm{~K}$ of the tested steels is summarized in Fig. 4. 0.5 mass $\%$ addition of $\mathrm{Mn}, \mathrm{Ru}$, 


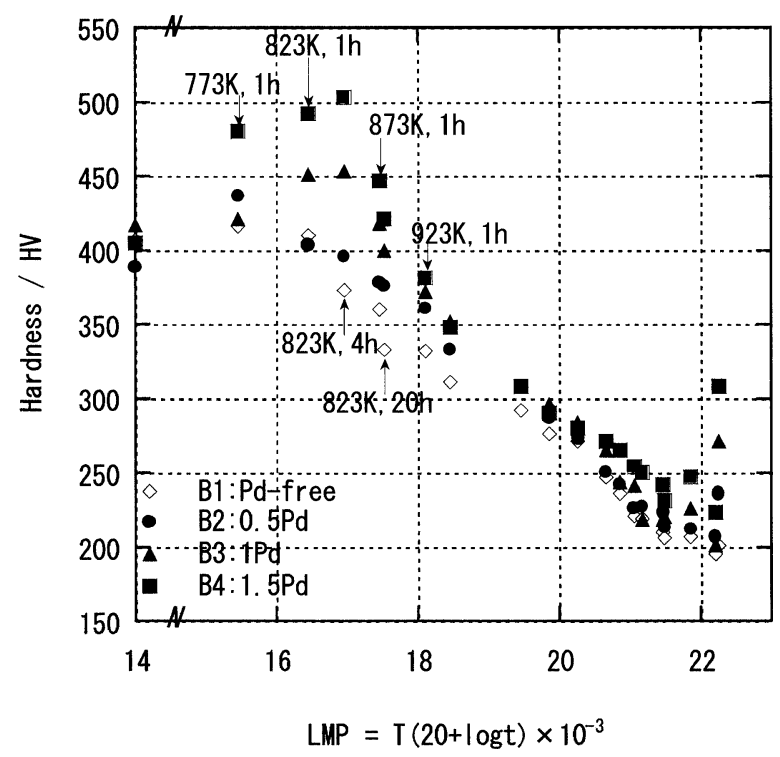

Fig. 2. Tempering parameter dependence of the hardness showing the precipitation hardening around $823 \mathrm{~K}$.

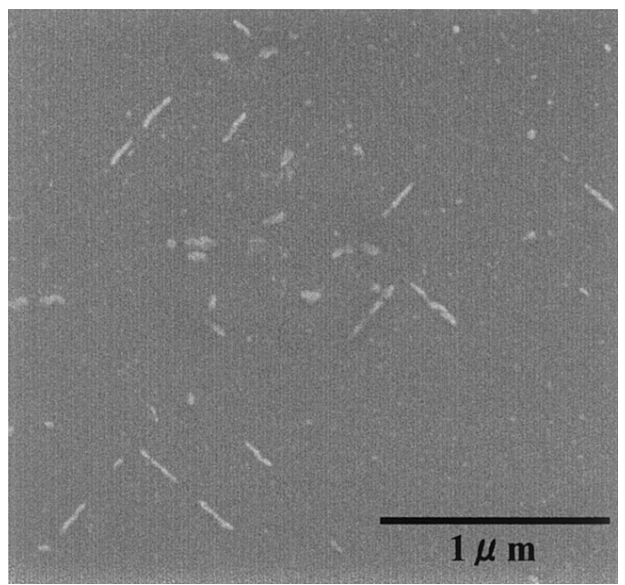

Fig. 3. Secondary electron image of $\mathrm{B} 4$ steel after tempering for $20 \mathrm{~h}$ showing the $\mathrm{Fe}-\mathrm{Pd} \mathrm{L1} 1_{0}$ ordered phase which is precipitated coherently to the bcc matrix.

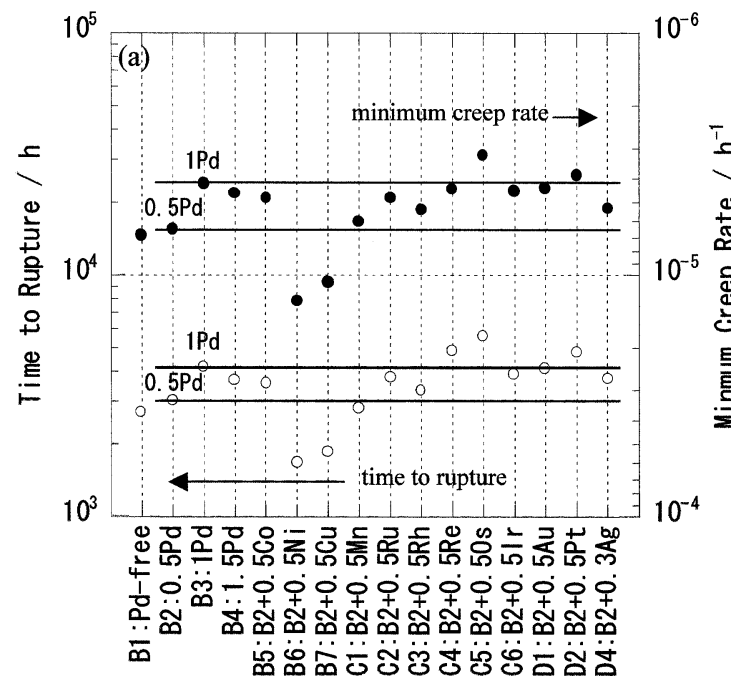

Rh, Re, Os, Ir, Au or Pt hardened the $0.5 \%$ Pd steel to the $1 \% \mathrm{Pd}$ steel level. These metals were expected to dissolve in $\alpha^{\prime \prime}$ and to increase the volume fraction of $\alpha^{\prime \prime}$ comparing to that of $0.5 \% \mathrm{Pd}$ steel.

Figures 5(a) and 5(b) show the effect of alloying elements on the time to rupture and the minimum creep rate crept at $923 \mathrm{~K}$ with 120 and $100 \mathrm{MPa}$, respectively. Minimum creep rate axis is reversed so that the data correspond to the time to rupture. Corresponding to the changes of the hardness, additions of $\mathrm{Ru}, \mathrm{Re}, \mathrm{Os}, \mathrm{Ir}, \mathrm{Au}$ or Pt decreased the minimum creep rate and increased the creep rupture life to the level of $1 \% \mathrm{Pd}$ steel, as shown in Fig. 5(a). Figure 6 shows the time dependence of creep rate for $\mathrm{C} 1, \mathrm{C} 4$ and $\mathrm{C} 5$ comparing with B1, B2 and B3. Addition of Re or Os not only decreased the minimum creep rate but also delayed the acceleration creep and prolonged the creep rupture life. Furthermore, C4 showed superior creep resistance to other steels under lower stress condition, as indicated by the smallest minimum creep rate in Fig. 5(b). While, although increase of the Mn concentration hardened the steel after aging at $823 \mathrm{~K}$, no improvement of creep re-

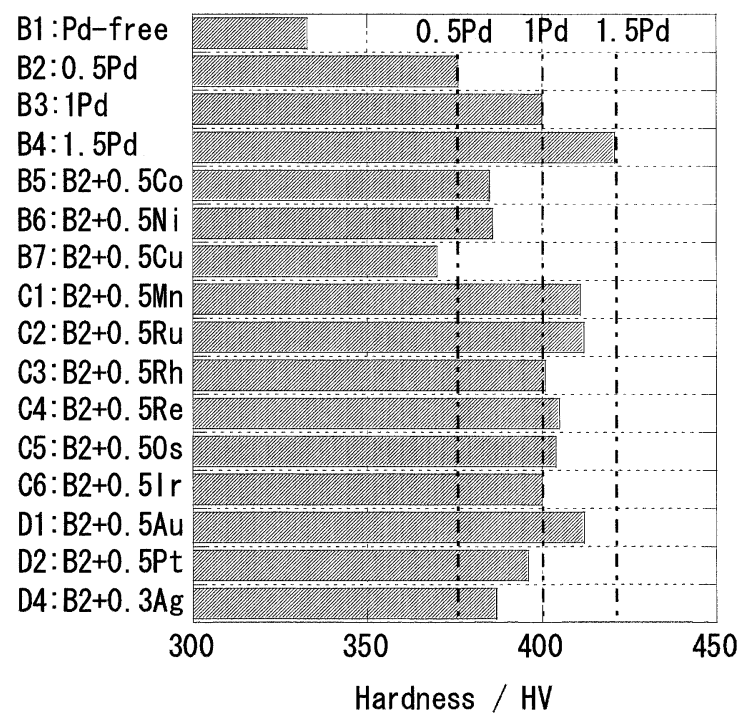

Fig. 4. Comparison of hardness after $20 \mathrm{~h}$ tempering at $823 \mathrm{~K}$ for the tested steels.

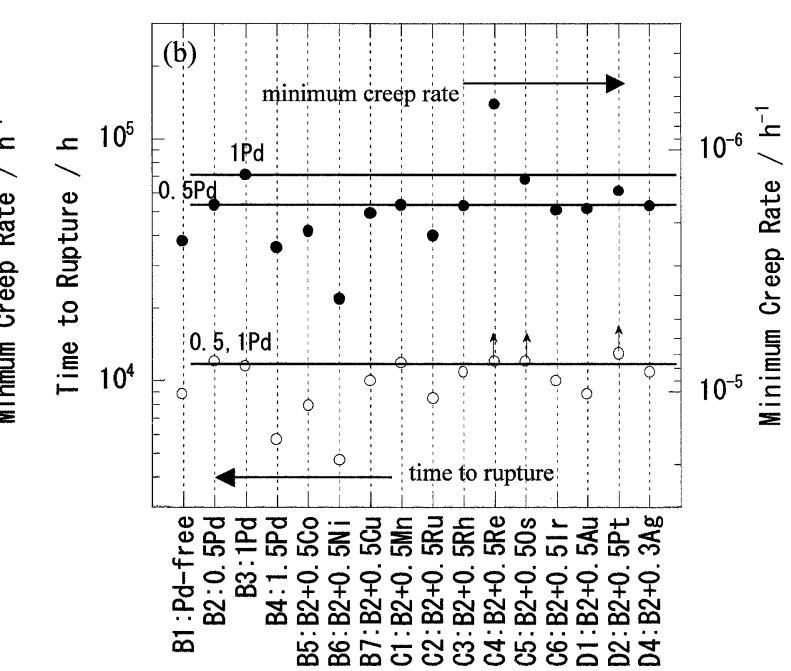

Fig. 5. Time to rupture and minimum creep rate of the tested steels crept at $923 \mathrm{~K}$ with $120 \mathrm{MPa}$ (a) and $100 \mathrm{MPa}$ (b). C4, C5 and D2 in Fig. 5(b) are still testing. 


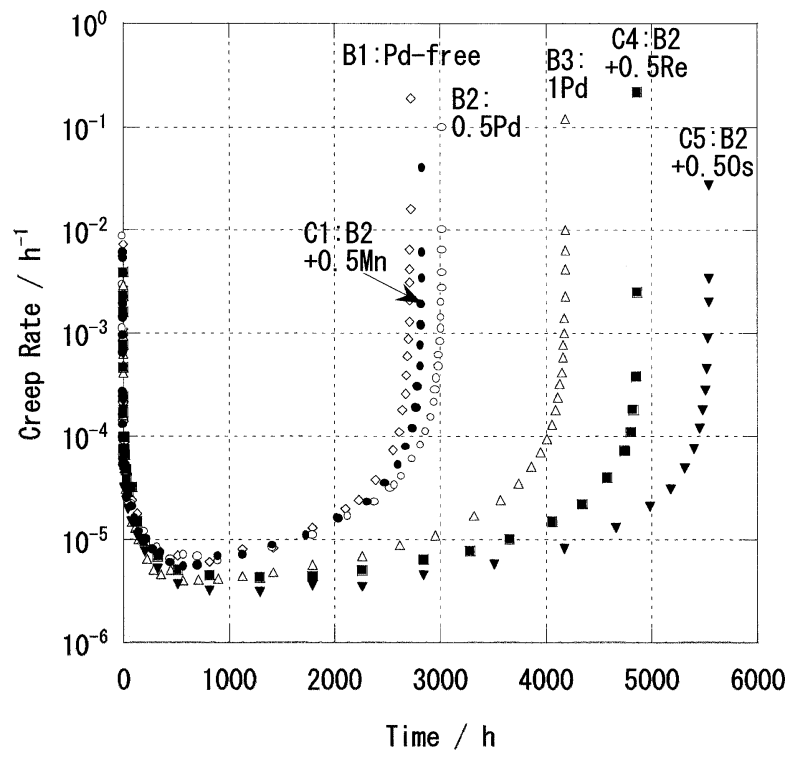

Fig. 6. Typical time vs. creep rate curves of the tested steel crept at $923 \mathrm{~K}$ and $120 \mathrm{MPa}$.

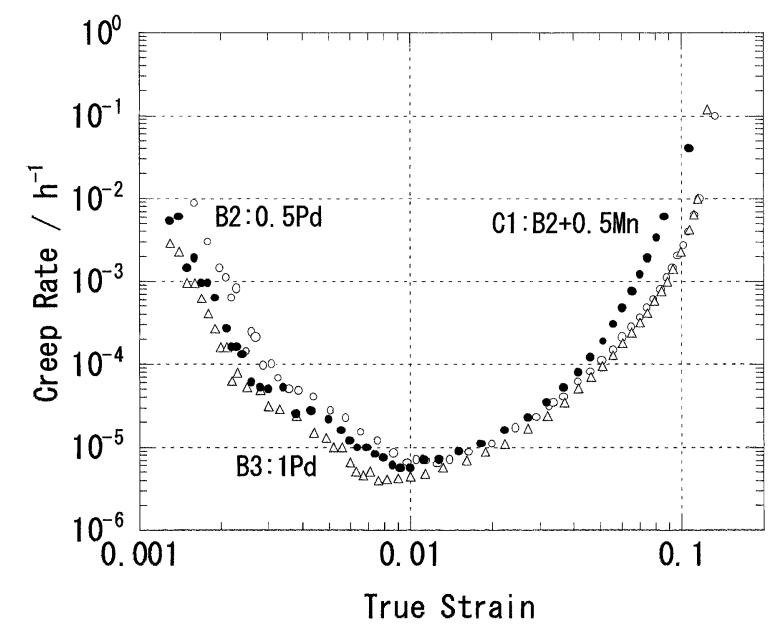

Fig. 7. True strain vs. creep rate curve of $\mathrm{C} 1$ steel comparing with B2 and B3 steels.

sistance was observed. True strain $v s$. creep rate curve of C1 steel is shown in Fig. 7. Increase of Mn decreased the creep rate at the early stage of primary creep to the level of $\mathrm{B} 3$, but the creep rate came close to $\mathrm{B} 2$ at the minimum creep and rapidly increased at the end of the tertiary creep.

B4 steel showed the degradation of creep properties by excess addition of $\mathrm{Pd}$, as shown in Fig. 5(b). Figure 8 shows the time-strain curves of B2, B3 and B4 crept at $923 \mathrm{~K}$ with $100 \mathrm{MPa}$. A sudden rupture at the early stage of tertiary creep was observed in B4 steel. It was suggested that too much addition of fine precipitation such as $\alpha^{\prime \prime}$ and MX carbonitride deteriorated the creep ductility resulting in the reduction of creep rupture life.

Paying attention to $\mathrm{C} 1$ and $\mathrm{C} 4$, precipitation behavior of these steels was evaluated by quantitative analysis of extracted residue and microstructural observation by SEM. Figure 9 shows the amount of precipitates of B1, B2, B3, $\mathrm{C} 1$ and $\mathrm{C} 4$ after crept at $923 \mathrm{~K}$ and $120 \mathrm{MPa}$. The amount of $\mathrm{Mn}$ in precipitates depended on that of $\mathrm{Pd}$ in precipitates, suggesting the Mn dissolution in $\alpha^{\prime \prime}$. The $\mathrm{Pd}$ to $\mathrm{Mn}$ ratio in precipitates was about 0.5 so that the amount of $\mathrm{Mn}$ in pre-

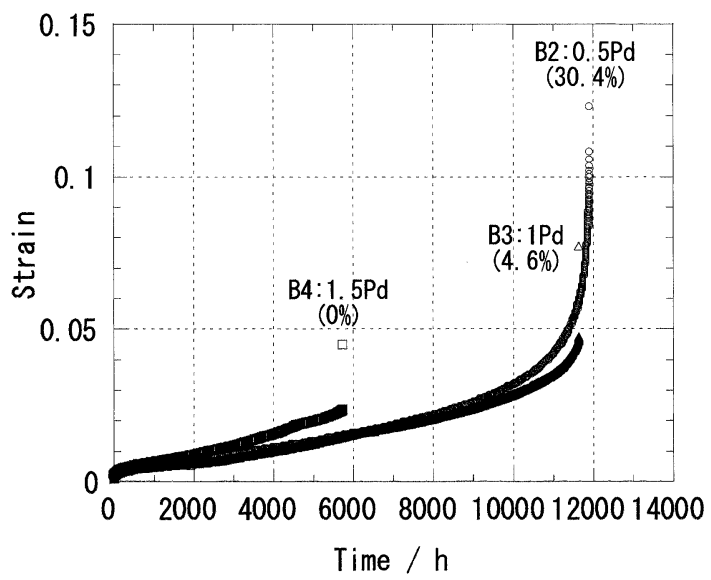

Fig. 8. Effects of Pd concentration on time-strain curves crept at $923 \mathrm{~K}$ and $100 \mathrm{MPa}$. Reduction of area is also indicated in the figure.

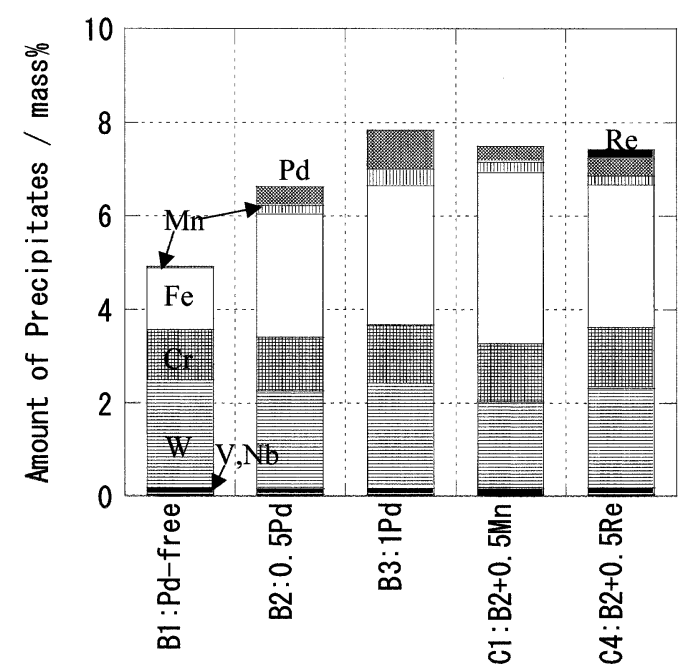

Fig. 9. Amount of precipitates for ruptured specimens crept at $923 \mathrm{~K}$ and $120 \mathrm{MPa}$.

cipitates was limited to only 0.2 mass $\%$, which was less than the concentration of $\mathrm{Mn}$ in $\mathrm{B} 2$ steel, in the case of $0.5 \% \mathrm{Pd}$ steel. It was suggested that the Mn addition promoted the precipitation of $\alpha^{\prime \prime}$, but in the saturated condition the amount of $\alpha^{\prime \prime}$ for $\mathrm{C} 1$ was almost equivalent to that for B2. As a result, $\mathrm{C} 1$ showed superior creep resistance to B2 in the early stage of primary creep but came close to B2 on the way to the minimum creep.

Figure 10 shows the back scattered electron images of ruptured specimen crept at $923 \mathrm{~K}$ with $120 \mathrm{MPa}$ for B2, B3, $\mathrm{C} 1$ and $\mathrm{C} 4$. Prior austenite, packet and block boundaries of $\mathrm{B} 2$ and $\mathrm{B} 3$ were decorated with $\mathrm{M}_{23} \mathrm{C}_{6}$ (gray precipitates in Fig. 10) and Laves phase (bright one in Fig. 10). And there was no clear difference in boundary decoration between B2 and B3. Poor boundary decoration was observed in Mn increased steel. On the contrary, continuous precipitation along boundaries and fine Laves phase inside lath were observed in Re-added steel. It was assumed that the growth of the precipitations in $\mathrm{C} 1$ accelerated the tertiary creep, as shown in Fig. 7, and the continuous precipitations in $\mathrm{C} 4 \mathrm{de}-$ layed the transition to tertiary creep, as shown in Fig. 6, by stabilizing the boundaries. It was also assumed that the fine Laves precipitates in $\mathrm{C} 4$ reduced the minimum creep rate 

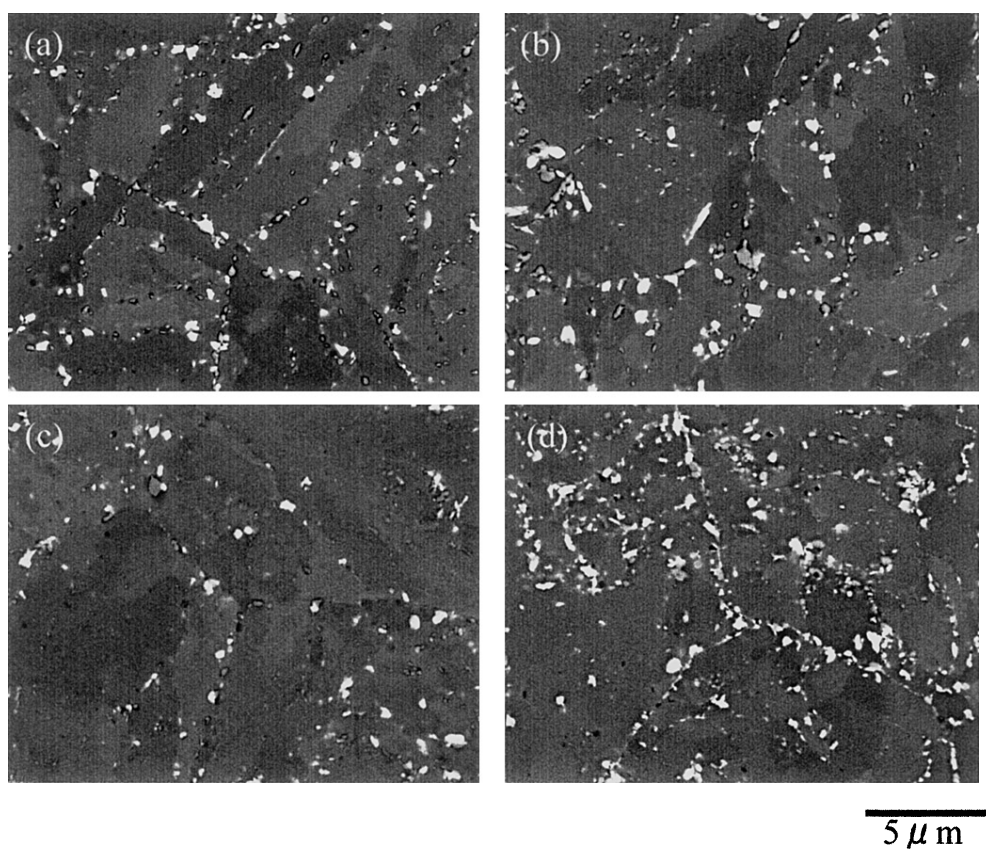

Fig. 10. Back scattered electron images of crept specimen. (a) $B 2, t R=3021 \mathrm{~h}$, (b) $B 3, t R=4182 \mathrm{~h}$, (c) $\mathrm{C} 1, \mathrm{t}=2829 \mathrm{~h}$, (d) $\mathrm{C} 4, \mathrm{tR}=4857 \mathrm{~h}$.
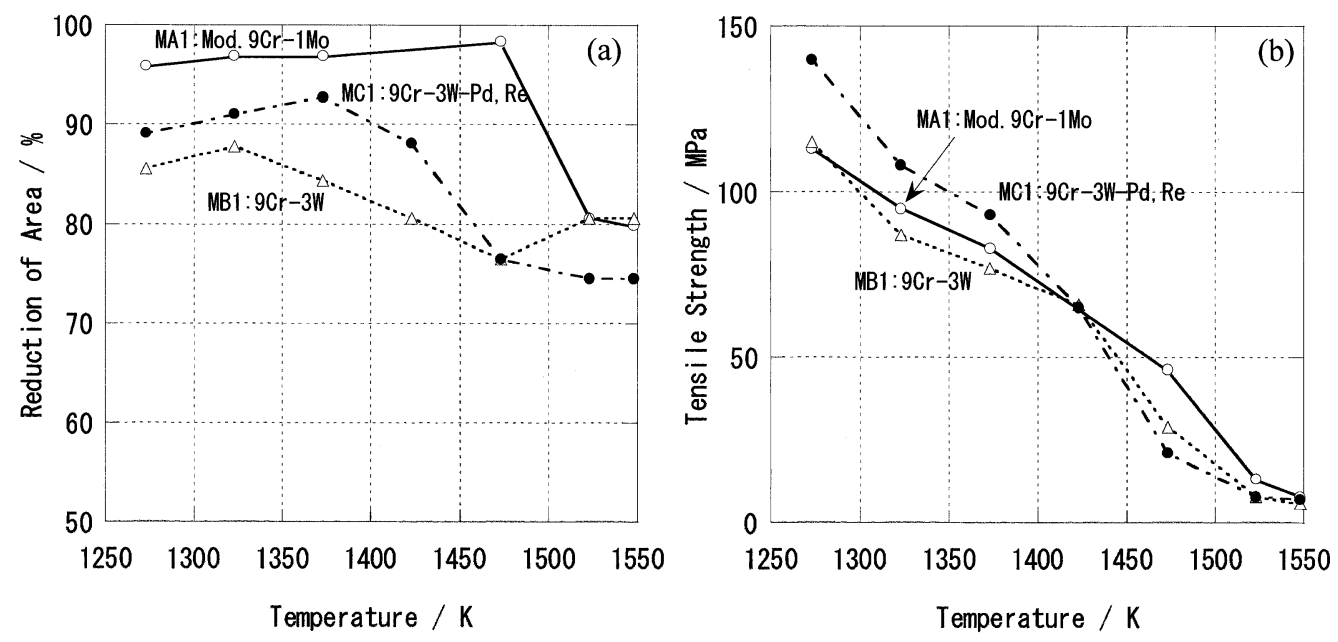

Fig. 11. High strain rate tensile test results, reduction of area (a) and tensile strength (b) for three kinds of steel plates.

remarkably, as shown in Fig. 5(b).

\subsection{Pipe Fabrication and Welding Test}

From the fundamental test results, $\mathrm{C} 4$ steel was selected for this test. Chemical composition of MC1 and MC2 was slightly modified from $\mathrm{C} 4$, as shown in Table 2, concerning the improvement of creep properties. $\mathrm{N}$ was decreased to 0.03 mass $\%$ to decrease fine precipitation of MX instead of $\alpha^{\prime \prime}$ in order to increase the creep ductility. Mn was decreased slightly to prevent the growth of precipitations such as Laves phase. $\mathrm{C}, \mathrm{Si}$ and $\mathrm{W}$ were also changed slightly to get the fully martensitic structure.

First, high temperature ductility was evaluated to judge the possibility of pipe fabrication by hot forging and extrusion process. Figure 11 shows the high strain rate tensile test results for MA1, MB1 and MC1. Reduction of area for MC1 kept more than $70 \%$ around hot forming temperature and the tensile strength was not remarkably higher than that of modified $9 \mathrm{Cr}-1 \mathrm{Mo}$ steel. In hot rolling and hot extrusion process, surface defects such as cracking occur, when the reduction in area of the steel is less than $60 \%{ }^{13)}$ From these results, pipe fabrication was done and succeeded without harmful defects.

Then, the plates were welded by gas tungsten arc welding. All plates were also welded successfully without defects. Figure 12 shows the optical microstructure of the welded joints. The formation of $\delta$-ferrite was observed in near fusion line of MB1 joint. While MC1 joint showed fully martensitic structure even along the fusion line. The Charpy impact properties of the welded joints at $273 \mathrm{~K}$ are shown in Fig. 13. Although the values of absorbed energies of the MC1 joint were lower than that of modified $9 \mathrm{Cr}-1 \mathrm{Mo}$ steel joint, the values still fulfilled the requirements for the practical use. 

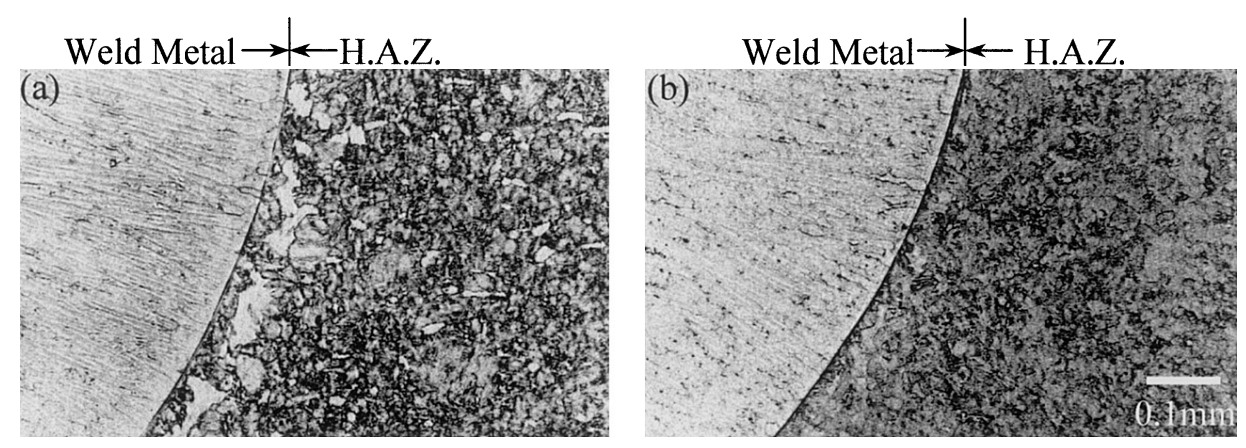

Fig. 12. Optical microstructure of welded joints for MB1 (a) and MC1 (b) after post welding heat treatment.

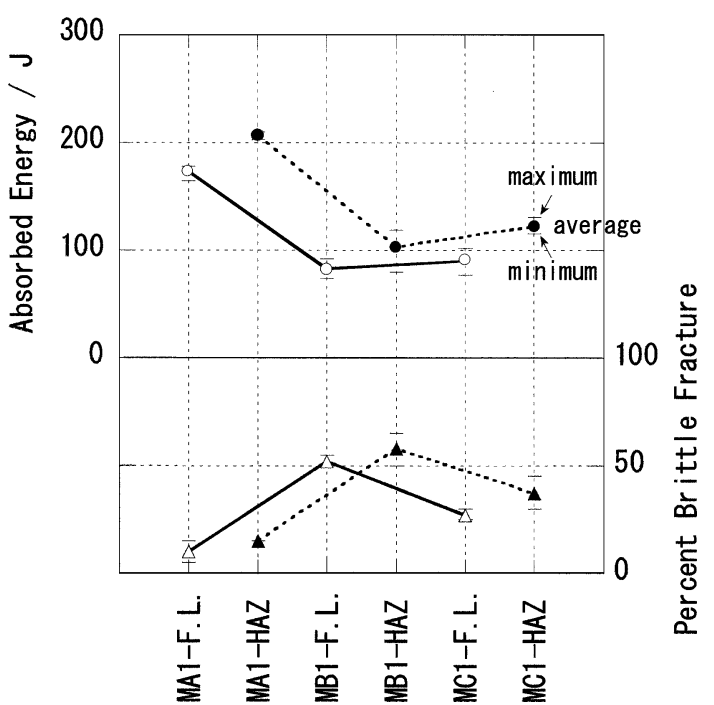

Fig. 13. Charpy impact properties of welded joints at $273 \mathrm{~K}$. $2 \mathrm{~mm}-\mathrm{V}$ notch is on the fusion line (F.L.) or heat affected zone (HAZ) of $10 \times 10 \times 55 \mathrm{~mm}$ specimen.

\section{Conclusion}

In order to search for substitutional element for the precious metal Pd, effects of alloying elements on creep properties of Pd-added 9Cr ferritic steels have been evaluated. Following results were acquired:

(1) Addition of Ru, Re, Os, Ir, Au or Pt hardened the $0.5 \mathrm{Pd}$ steel after tempering at precipitation temperature of $\alpha^{\prime \prime}$ and also improve the creep property to the $1 \%$ Pd steel level.

(2) Increase of Mn concentration promoted the precipitation of $\alpha^{\prime \prime}$ but did not increase the amount of $\alpha^{\prime \prime}$, resulting in no improvement of creep properties.

(3) Re addition prevented the growth of precipitation such as $\mathrm{M}_{23} \mathrm{C}_{6}$ and Laves phase, resulting in improving the creep properties at lower stress level.

From the above fundamental test results, demonstrational pipe fabrication and welding tests were performed for $\mathrm{Pd}$ and Re added steel. Pd and Re added steel was successfully formed into pipe and welded without harmful defects.
Detailed creep properties of fabricated plates and pipes will be reported in near future.

\section{Acknowledgement}

The authors would like to thank Sumitomo Metal Technology for carrying out the pipe fabrication and the welding test.

\section{REFERENCES}

1) V. K. Sikka, C. T. Ward and C. Thomas: ASM Int. Conf. Production, Fabrication, Properties and Application of Ferritic Steels for HighTemperature Applications, ASM, Ohio, (1981).

2) F. Masuyama, I. Ishihara, T. Yokoyama and M. Fujita: Therm. Nucl. Power, 46 (1995), 498.

3) K. Muramatsu: Proc. Advanced Heat Resistant Steels for Power Generation, ed. by R. Viswanathan et al., The University Press, Cambridge, (1998), 543.

4) F. Masuyama: Proc. Advanced Heat Resistant Steels for Power Generation, ed. by R. Viswanathan and J. Nutting, The University Press, Cambridge, (1998), 33.

5) K. Sawada, M. Takeda, K. Maruyama, R. Ishii and M. Yamada: Proc. the 6th Liege Conf. on Materials for Advanced Power Engineering, ed. by J. Lecomte-Beckers et al., Forshungs-zentrum, Jülich GmbH, Jülich, (1998), I.575.

6) H. Nakashima: Proc. Int. Workshop on the Innovative Structural Materials for Infrastructure in 21st Century, NRIM, Tsukuba, (2000), 21.

7) M. Igarashi, S. Muneki and F. Abe: Proc. the 6th Liege Conf. on Materials for Advanced Power Engineering, ed. by J. LecomteBeckers et al., Forshungs-zentrum, Jülich GmbH, Jülich, (1998), I.673.

8) M. Igarashi, K. Yamada, S. Muneki and F. Abe: Proc. Int. Workshop on the Innovative Structural Materials for Infrastructure in 21st Century, NRIM, Tsukuba, (2000), 106.

9) K. Yamada, S. Muneki, M. Igarashi and F. Abe: Proc. Int. Workshop on the Innovative Structural Materials for Infrastructure in 21st Century, NRIM, Tsukuba, (2000), 114.

10) M. Igarashi, S. Muneki, H. Kutsumi, T. Itagaki, N. Fujitsuna and F. Abe: Proc. 5th Inter. Charles Persons Turbine Conf., ed. by A. Strang et al., The University Press, Cambridge, (2000), 334.

11) M. Igarashi, S. Muneki and F. Abe: Report of 123rd Committee on Heat-Resisting Metals and Alloys, Jpn. Soc. for the Promotion of Sci., Tokyo, 39 (1998), 355.

12) M. Igarashi, S. Muneki, H. Hasegawa, K. Yamada and F. Abe: ISIJ Int., 41 (2001), S101.

13) Kinzoku-binran, ed. by the Jpn. Inst. of Met., Maruzen, Tokyo, (1990), 1116. 